Vol 11, Issue 7, 2018

Online - 2455-3891

Print - 0974-2441

$\underline{\text { Research Article }}$

\title{
FORMULATION AND EVALUATION OF SUBMICRON EMULSION CONTAINING ENTRAPPED FLUOROQUINOLONE FOR OCULAR DELIVERY
}

\author{
DURGA PANDEY*, DEEPTI JAIN \\ School of Pharmaceutical Sciences, RGPV, Bhopal, Madhya Pradesh, India. Email: durga.pandey9@gmail.com Received: 04 January 2017,
}

Revised and Accepted: 25 April 2018

ABSTRACT

Objective: The objective of the present work was to develop and characterize the submicron emulsion bearing antimicrobial drug sparfloxacin (SF) for improvement of ocular activity by improved retention in eyes. The developed delivery system was results with prolonged drug release as compared to the conventional dosage form.

Methods: Submicron emulsion (SE) prepared by high energy emulsification and sonication to obtain uniform globule size.

Results: Average internal droplets size of the optimized formulation was $0.278 \pm 0.6 \mu \mathrm{m}$, pH of the optimized formulation was $6.9 \pm 0.6$ (average of three determinations), and viscosity $2.9 \pm 0.5 \mathrm{cps}$ suitable for ocular use. Entrapment of SF was $63 \pm 3.4 \%$. Prepared formulation was found to be stable under accelerated and long term storage at 4 and $37^{\circ} \mathrm{C}$. No major changes reported on $\mathrm{pH}$ and viscosity of optimized formulations. In vitro, drug release pattern showed sustain release of SF, a cumulative percent release of SF was found $87.8 \pm 1.7 \%$ within 24 h. Transmission electron microscopy showed spherical shape and size within $1 \mu \mathrm{m}$.

Conclusion: Designed formulation can be a good candidate for ocular drug delivery for severe ocular infections where frequent dosing required for conditions such as endophthalmitis, corneal ulcer, and penetrating trauma.

Keywords: Ocular, Submicron emulsion, Antimicrobial, Prolonged drug release.

(C) 2018 The Authors. Published by Innovare Academic Sciences Pvt Ltd. This is an open access article under the CC BY license (http://creativecommons. org/licenses/by/4. 0/) DOI: http://dx.doi.org/10.22159/ajpcr.2018.v11i7.24608

\section{INTRODUCTION}

Delivery of drugs to the eye remains a challenge for physicians as well as pharmaceutical scientists. The conventional formulations available commercially for ocular drug delivery are associated with various problems such as loss of drug from drainage, induced lacrimation, normal tear turn over, enzymes present in precorneal area, and low conjunctival absorption $[1,2]$. Anterior segment of the eye diseases treated with eye drop solutions, unfortunately, these are rapidly drained from the ocular surface and absorption is about $<5 \%$. Nanoemulsions with average droplet size are between 100 and $500 \mathrm{~nm}$, stabilized suitable surfactants, and cosurfactants improve penetration of drugs in deep ocular infections [3]. The nanoemulsion offers a sustained release effect and high penetration of the drug through the cornea. This would, therefore, provide the advantages of conventional eye drops (ease of application and high patient compliance) and eliminate their disadvantages (low bioavailability and frequent administration) [4-6].

The term submicron emulsion (SE) is applied to emulsions that possess a dispersed phase mean droplet diameter under $1 \mu \mathrm{m}$ and also referred to as miniemulsion, ultrafine emulsions, nanoemulsions [7]. Phase behavior studies have shown that size of the droplets governed by the surfactant phase structure (bicontinuous microemulsion or lamellar) at the inversion point induced by either temperature or composition [8]. SE can be given by a variety of route such as parenteral, topical, ophthalmic, and nasal delivery and as a vehicle in cosmetics. As compared to conventional ocular dosage form, SE gives better retention time into the eye. Long duration of action reduces the dosage frequency and patient compliance [9]. Fluoroquinoles are very effective for the treatment of severe ocular infection, Sparfloxacin (SF) is bacterial DNA gyrase (topoisomerase IV) inhibitor, and it inhibits DNA replication and transcription [10].

The aim of this study was to load drug, sparfloxacin in submicron emulsion for prolonged drug release and more retention in precorneal area. Designed formulation reduces the side effects of conventional dosage form due to more targeting in ocular globe. Novelty in work was $\mathrm{SE}$, composed of lecithin and poloxamer for selected drug not available in market.

\section{MATERIALS AND METHODS}

Materials

All chemicals were of analytical grade. SF received as a gift sample from Orbit Pharmaceutical, and poloxamer 188, Soya lecithin, and Soya oil purchased from Loba Chemie.

\section{Methods}

Preformulation studies

Solubility of drug determined by equilibrium solubility method and drug identification done by Fourier- transform infrared spectroscopy (FTIR). The infrared spectral assignment of SF was obtained in $\mathrm{KBr}$ using FT-IR prestige spectrophotometer.

$\mathrm{pH}$ determined by digital $\mathrm{pH}$ meter (mkow optics).

$\lambda_{\max }$ determined by ultraviolet (UV)-visible spectrophotometer [Fig. 1] (UV-1700 Shimadzu Corporation, Japan).

\section{Drug and excipient compatibility studies}

FTIR spectra analysis: Levels of investigations:

- SF Fig. 2.

- SF+soya lecithin Fig. 3.

- $\mathrm{SF}+$ poloxamer Fig. 4.

SE preparation [11-13].

Various formulations were prepared by changing excipient concentration, and drug concentration was equivalent to the marketed 
formulation in all batches and prepared by standard procedure with minor modifications [14].

Step I - Preparation of oil phase: - Fixed amount of soya oil and egg lecithin taken and stirred properly in a magnetic stirrer at temperature $60^{\circ} \mathrm{C}$, then finally drug added and stirred until it was mixed completely.

Step II - Preparation of aqueous phase: - Fixed amount of water mixed with poloxamer 188 with continuous stirring.

Step III - Oil phase was added to water phase dropwise with continuous

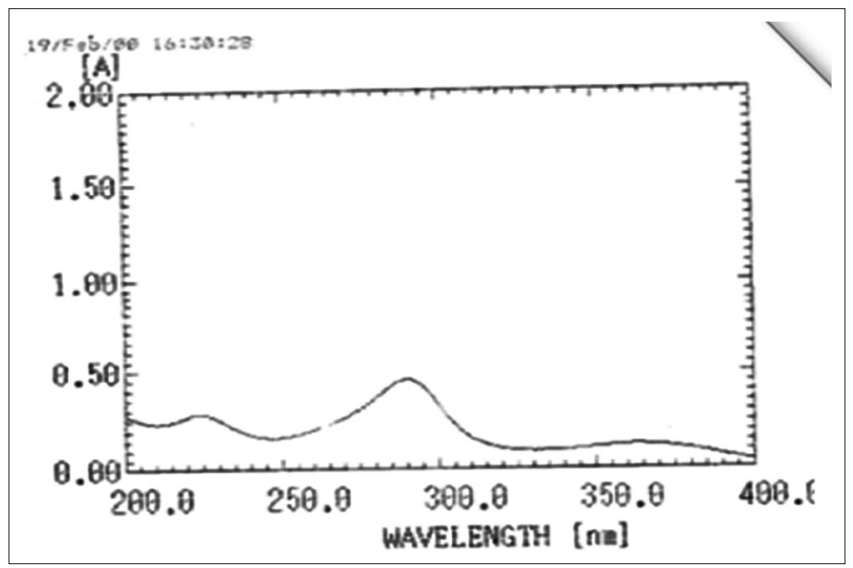

Fig. 1: Absorption maximum of sparfloxacin stirring in high shear mixer until both the phases mixed completely. Then, this emulsion was subjected to sonication in probe sonicator for 10 min Table 1.

Evaluation of SE [15]

Various parameters were observed during studies like-particle size: Droplets size and size distribution of emulsion system were determined using Malvern Mastersizer 2000 laser diffraction particle analyzer (Malvern Instruments).

Transmission electron microscopy (TEM) was also performed using negative staining with sodium phosphotungstate solution $(0.2 \% \mathrm{w} / \mathrm{v})$. The formulation was dispersed in the staining solution for $30 \mathrm{~min}$ at room temperature, placed on a copper grid covered with nitrocellulose, dried under vacuum for at least $24 \mathrm{~h}$ and observed under TEM (TEM1200 EX Japan) [Fig. 5] pH: Determined by digital pH meter. Viscosity: The viscosity of SE of SF was determined by brook field viscometer.

Drug entrapment efficiency: The SF loaded emulsions were centrifuged at $18,000 \times \mathrm{g}$ and $4^{\circ} \mathrm{C}$ for $15 \mathrm{~min}$ in ultracentrifuge to separate free drug from the entrapped drug. After centrifugation, the supernatant was collected and analyzed by UV visible spectrophotometer at $289 \mathrm{~nm}$ for the free drug or unentrapped drug (A1) concentration to determine the encapsulation efficiency from the total amount of drug (A2).

$\mathrm{EE} \%=(\mathrm{A} 2-\mathrm{A} 1 / \mathrm{A} 2) \times 100$

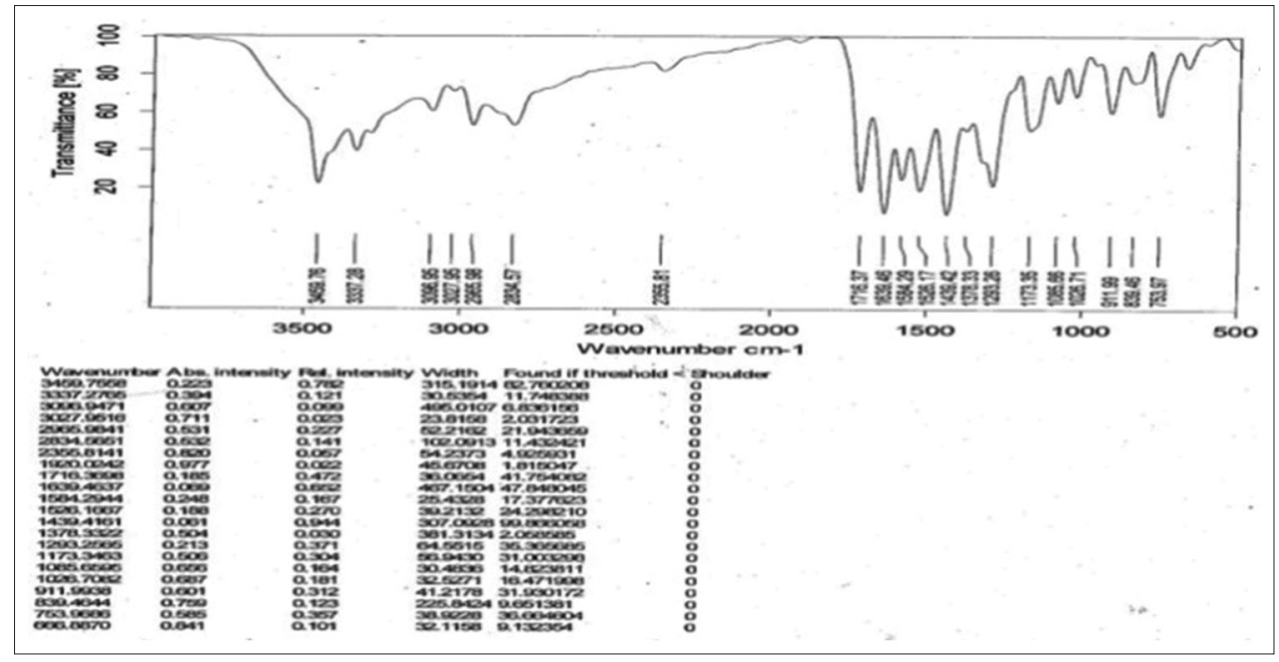

Fig. 2: Fourier transform infrared spectra of sparfloxacin

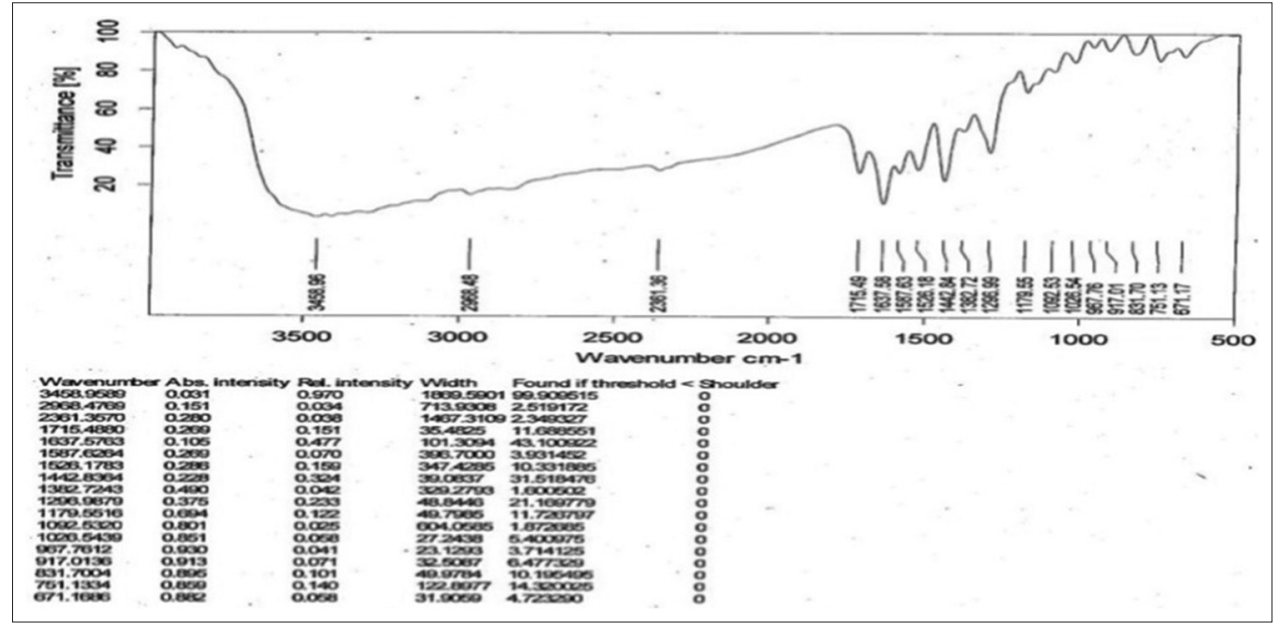

Fig. 3: Fourier transform infrared spectra of sparfloxacin+soya lecithin 


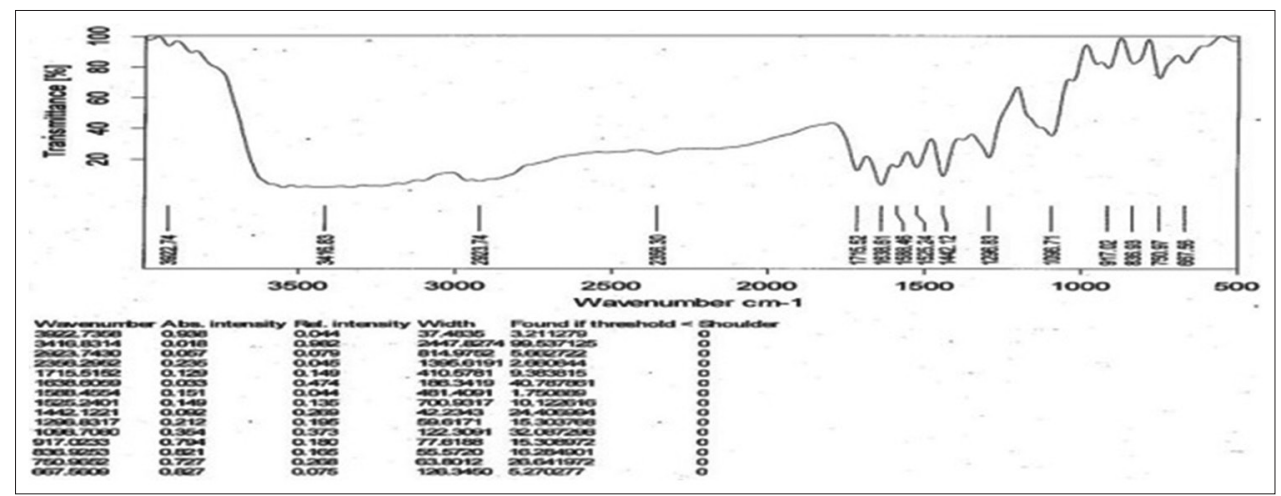

Fig. 4: Fourier transform infrared spectra of sparfloxacin+poloxamer 188

Table 1: Composition of optimized formulations $(\% \mathrm{w} / \mathrm{w})$

\begin{tabular}{lll}
\hline Excipients & SE & SE-SF \\
\hline Soya oil & 10 & 10 \\
Poloxamer 188 & 2.5 & 2.5 \\
Egg lecithin & 1.25 & 1.25 \\
SF & - & 0.3 \\
Water & 100 & 100 \\
\hline
\end{tabular}

SE: Submicron emulsion, SF: Sparfloxacin

Stability assessment: During stability, different parameters such as the drug content, $\mathrm{pH}$, and droplet size distribution were monitored over periods of 90 days stored at $4^{\circ} \mathrm{C}, 23^{\circ} \mathrm{C}$, and $37^{\circ} \mathrm{C}$ [16]. The creaming and the phase separation were assessed visually at different time intervals. To evaluate its mechanical and physical resistance, the emulsion was subjected to accelerated mechanical stress and its globule size distribution was measured before and after shaking at 100 strokes per min over $48 \mathrm{~h}$ at room temperature $[17,18]$.

In vitro drug release: The in vitro release profile of SE was performed using dialysis bag technique [19]. The $\mathrm{SE}$ within dialysis bag immersed into $100 \mathrm{ml}$ of phosphate buffer solution, $\mathrm{pH} 7.4$ at $37^{\circ} \mathrm{C}$, and magnetically stirred at $100 \mathrm{rpm}$. Aliquots were withdrawn from the release medium and replaced with the same amount of the phosphate buffer to maintain sink condition. The data obtained from in vitro drug release studies were fitted to various release models such as zero-order, first-order, Higuchi, and Korsmeyer's-Peppas model to understand the mechanism of drug release from the emulsion. The content of SF from the withdrawn sample was measured after dilution at UV visible spectrophotometer at $289 \mathrm{~nm}[20,21]$.

\section{RESULTS}

\section{Solubility}

The solubility of the drug was found in $0.1 \mathrm{~N}$ sodium hydroxide and dilute acetic acid. Melting point was found to be $262-265^{\circ} \mathrm{C}$.

\section{pH and viscosity of the SE}

Observed $\mathrm{pH}$ was $6.9 \pm 0.6$ (average of three determinations), and viscosity of SE was found $2.9 \pm 0.5 \mathrm{cps}$ (average of three determinations).

\section{Mean particle size}

Mean particle size was found to be $0.278 \pm 0.6 \mu \mathrm{m}$.

\section{Drug entrapment efficiency}

The drug entrapment in the SE was found to be $63 \pm 3.4 \%$.

\section{Drug excipient compatibility}

Drug-excipient compatibility studies done using FT-IR spectroscopy. The drug was compatible with excipient as found in FT-IR analysis.

SE was a plain formulation without drug and SE-SF contained SF in a concentration equivalent to the marketed formulation.

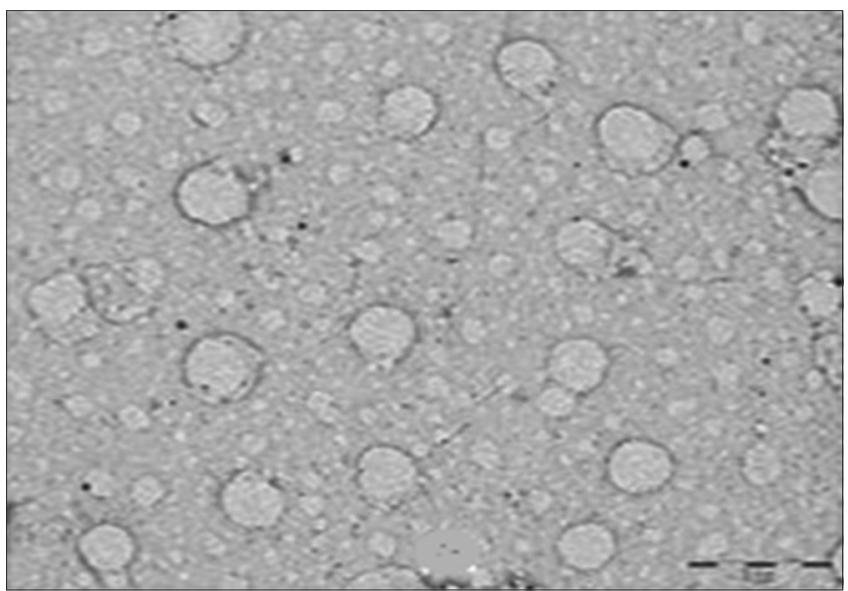

Fig. 5: Transmission electron microscopy of submicron emulsionsparfloxacin Stability studies of optimized formulation in Table 2 showing stability study data of optimized formulation.

The storage stability of formulations was checked in terms of change in globules size, viscosity, and $\mathrm{pH}$ of emulsion sample stored at $4^{\circ} \mathrm{C}$ and $37^{\circ} \mathrm{C}$ over a period of 3 months, no major changes noticed. Values are expressed as means of three different batches.

\section{DISCUSSION}

SF available as eye drops for corneal and conjunctival infection but $<1 \%$ bioavailability observed [22]. SE is more suitable than solutions, ointments, gels, and nanoparticles. Ointment improves retention but not comfortable due to the semisolid consistency of the preparations. Nanoparticles consisting of poly alkyl cyanoacrylate damaged the corneal epithelium by disrupting the cell membrane [23]. Blurred vision reported with gels as more viscous formulation than SE. SF entrapped successfully within oil phase of SE lecithin was used as surfactant and poloxamer 188 as cosurfactant. Various factors mentioned in Fig. 6 can be overcome by designed formulation. The appearance of SF was visually observed and complies with the standard limit. Melting point, UV and FT-IR spectroscopy of SF confirms that drug comply with standard specifications. The drug was practically insoluble in water so entrapped in the internal phase of oil in water emulsion. Cosurfactant is very essential for the stability of SE $[24,25]$. Poloxamer 188 concentration is critical for prolonged emulsion stability [26]. Formulations were prepared below $70^{\circ} \mathrm{C}$ as higher temperature degrades lecithin.

Optimization of batch was done by evaluation of their droplets size, viscosity, $\mathrm{pH}$, and stability. The $\mathrm{pH}$ of the optimized formulation was satisfactory and suitable for ocular use. The average globule size in the dispersed phase of the formulation was in submicron range indicated its suitability for ocular use. As particle size requirement in such cases is $<2 \mu \mathrm{m}$ [27]. Sonication of formulations further reduces 
the droplets size. Homogenization speed also plays an important role to achieve submicron size as speed more than 15000 results with a reduction in droplets size [28]. The drug content in the SE was found to be $63 \pm 3.4 \%$ represents sufficient entrapment of drug in the internal phase. Viscosity and $\mathrm{pH}$ of final formulation indicate its suitability for the ocular route. Viscosity for ocular use reported, 2-3 cps considered as adequate viscosity for ocular preparation [3]. The data obtained from in vitro release studies of SE were satisfactory and showed sustained release profile Fig. 7 thus more drug retention is possible in the precorneal area. Release mechanism of the drug from formulation was due to diffusion and partition from oily core to the aqueous phase. TEM confirms spherical shape and size within $1 \mu \mathrm{m}$ which is suitable for the ocular application. TEM freeze-fracturing examination revealed that a mixed-emulsifier monolayer film was established at the $\mathrm{o} / \mathrm{w}$ interface of the SE.

In stability studies, during the excessive shaking, no phase separation or creaming and change in mean droplet size observed because the interfacial film formed by lecithin and poloxamer was strong enough to prevent droplet coalescence on any physical and thermal condition.

\section{CONCLUSION}

From this study, it is concluded that the SE can be an effective dosage form for more retention in eyes. It has the convenience of drop and comfortable due to droplet size $<1 \mu \mathrm{m}$ and will improve the activity of $\mathrm{SF}$ as compare to another conventional ocular dosage form. The

Table 2: Long-term stability studies at $4^{\circ} \mathrm{C}$ and $37^{\circ} \mathrm{C}$ for 3 months

\begin{tabular}{llllll}
\hline Days & $\mathbf{p H}$ & Viscosity $\mathbf{c p}$ & Particle size $\boldsymbol{\mu m}$ & $\mathbf{p H}$ & Viscosity cps \\
\cline { 2 - 6 } & $\mathbf{4}^{\circ} \mathbf{C}$ & & & $\mathbf{3 7}{ }^{\circ} \mathbf{C}$ & \\
\hline 0 & $6.9 \pm 0.6$ & $2.9 \pm 0.5$ & $0.278 \pm 0.6$ & $6.9 \pm 0.6$ & $2.9 \pm 0.5$ \\
15 & $6.9 \pm 0.4$ & $2.2 \pm 0.6$ & $0.302 \pm 0.7$ & $6.9 \pm 0.3$ & $2.8 \pm 0.2$ \\
30 & $6.7 \pm 0.2$ & $2.3 \pm 0.6$ & $0.305 \pm 0.6$ & $6.9 \pm 0.3$ & $2.7 \pm 0.4$ \\
60 & $6.5 \pm 0.4$ & $2.4 \pm 0.3$ & $0.311 \pm 0.8$ & $6.7 \pm 0.3$ & $2.5 \pm 0.5$ \\
90 & $6.3 \pm 0.3$ & $2.4 \pm 0.6$ & $0.320 \pm 0.9$ & $6.4 \pm 0.3$ & $0.279 \pm 0.6$ \\
\hline
\end{tabular}

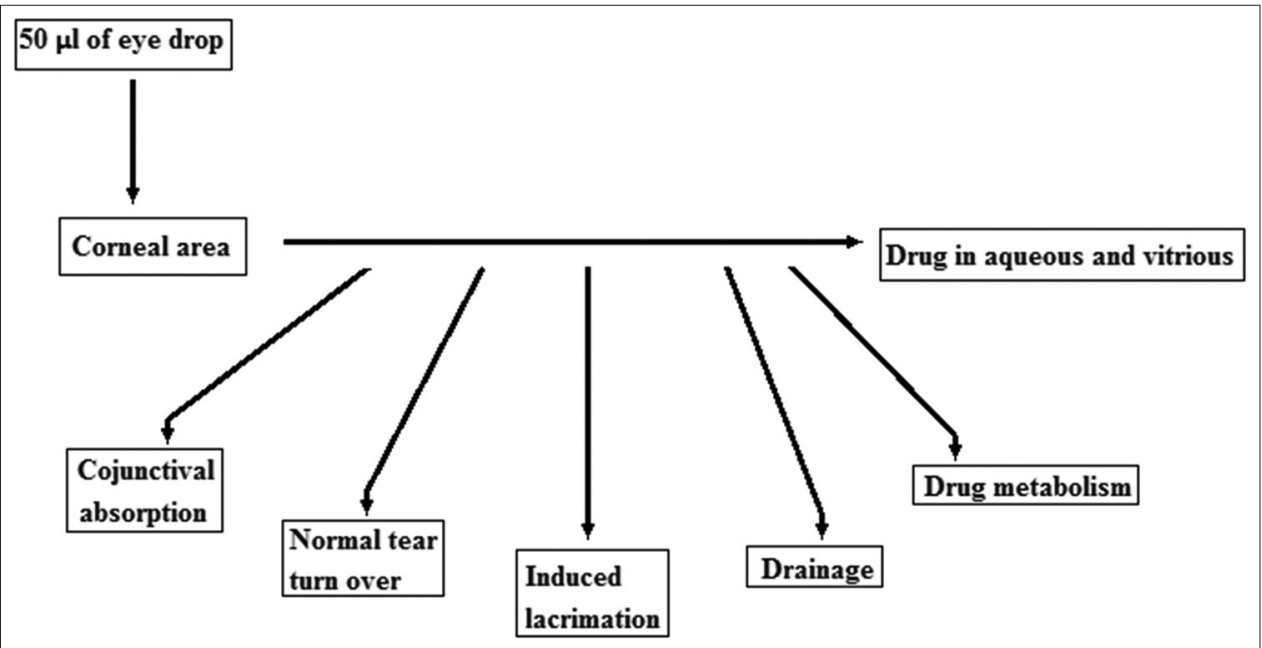

Fig. 6: Various factors competing corneal absorption [3]

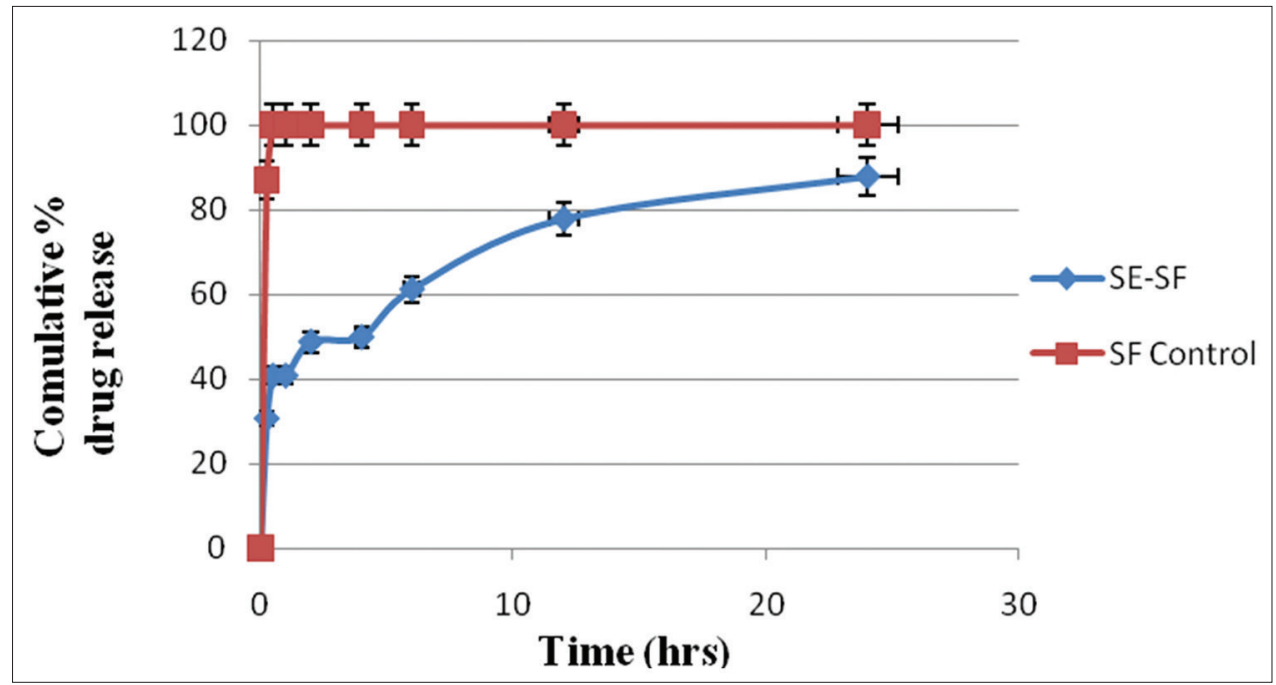

Fig. 7: In-vitro drug release behavior of sparfloxacin, prolonged release observed as compared to marketed control. $87.8 \pm 1.7 \%$ found in $24 \mathrm{~h}$. Data represented as a mean average value of three determinations $(n=3)$ 
discussed work will be benefitted by researchers and formulators for preparation of safe, stable, and effective formulation.

\section{ACKNOWLEDGMENTS}

Author Ms. Durga Pandey is thankful to the School of Pharmaceutical Sciences, Rajiv Gandhi Proudyogiki Vishwavidyalaya, Bhopal and Sagar Institutes of Research and Technology Pharmacy, Bhopal, for providing me facilities and support during my research work

\section{AUTHOR'S CONTRIBUTION}

Design of the study, all experimental work and data compilation done by author Durga Pandey under the guidance of Dr. Deepti Jain.

\section{CONFLICTS OF INTEREST}

Declared none.

\section{REFERENCES}

1. Preethi GB, Prashanth K. Design and evaluation of controlled-release ocular inserts of brimonidine-tartrate and timolol maleate. Int J Pharm Pharm Sci 2017;9:79-82.

2. Hamsika M, Gowda DV, Jigyasa V, Moin A. Nanotechnology for ophthalmic preparations. Int J Curr Pharm Res 2016;8:5-11.

3. Shunmugaperumal T, Simon B. The potential of lipid emulsion for ocular delivery of lipophilic drugs. Eur J Pharm Biopharm 2004;58:357-68.

4. Manoj KS, Sasmita P. Solid lipid nanoparticles-a review. J Crit Rev 2016;3:5-12

5. Pattravee N, Sriniva SP, Waree T. Development and characterization of indomethacin-loaded mucoadhesive nanostructured lipid carriers for topical ocular delivery. Int J App Pharm 2018;10:91-6.

6. Morsi NM, Mohamed MI, Refai H, Elsorogy HM. Nanoemulsion as a novel ophthalmic delivery system for acetazolamide. Int J Pharm Pharm Sci 2014;6:227-36.

7. Solans C, Izquierdo P, Nolla J, Azamar N, Garcia C. Nanoemulsion. Curr Opin Coll Interface Sci 2005;10:102-10

8. Kaur IP, Garg A, Singla AK, Aggarwal D. Vesicular systems in ocular drug delivery: An overview. Int J Pharm 2004;269:1-14.

9. Vandamne TF. Microemulsion as ocular drug delivery system: Recent development and future challenges. Prog Retin Eye Res 2004;21:15-34.

10. Tripathi KD. Essential of Medical Pharmacology. $7^{\text {th }}$ ed. New Delhi: Jaypee Brother Medical Publisher; 2015.

11. Vyas SP, Khar RK. Targeted and Controlled Drug Delivery Novel Carrier System. $1^{\text {st }}$ ed. New Delhi: CBS Publishers and Distributers; 2008

12. Yujin $\mathrm{H}$, Jae KL, Jong KL, Young MJ, Seong-ir C, Ahn YC, et al.
Production and dispersion stability of nanoparticles in nanofluids. Powder Technol 2008; 186:145-53

13. Leong TS, Wooster TJ, Kentish SE, Ashok KM. Minimising oil droplet size using ultrasonic emulsification. Ultrason Sonochem 2009;16:721-7.

14. Gregori BR, Cornelia MK, Nadia AB. Development of cationic nanocrystals for ocular delivery. Eur J Pharm Biopharm 2016;107:215-22.

15. Jain V, Singidiya D, Gupta GK, Garg D, Mishra PR. Ciprofloxacin surf-plexes in submicron emulsion: Anovel approach to improve payload efficiency and antimicrobial efficacy. Int J Pharm 2011;409:237-44.

16. Benita S, Levy MY. Submicron emulsions as colloidal drug carriers for intravenous administration: Comprehensive physicochemical characterization. J Pharm Sci 1993;82:1069-79.

17. Shi YC, Benita S. Enhanced absorption and drug targeting by positively charged submicron emulsions. Drug Dev Res 2000;50:476-86.

18. Klang SH, Abdulrazik M, Benita S. Influence of emulsion droplet surface charge on indomethacin ocular tissue distribution. Pharm Dev Technol 2000;5:521-32.

19. Ibrahim SS, Awad GA, Geneidi A, Mortada ND. Comparative effects of different cosurfactants on sterile prednisolone acetate ocular submicron emulsions stability and release. Colloids Surf B 2009;69:225-31.

20. Levy MY, Benita S. Drug release from submicronized o/w emulsion: A new in vitro kinetic evaluation model. Int J Pharm 1990;66:29-37.

21. Jankie S, Amusa AS, Gopala KP. In vitro activity of fluroquinolones entrapped in non ionic surfactant vesicles against ciprofloxacin resistant bacteria strains. J Pharmtech Drug Res 2012;120:1-10.

22. Gupta H, Aqil M, Khar RK, Ali A, Bhatnagar A, Mittal G. Sparfloxacin-loaded PLGA nanoparticles for sustained ocular drug delivery. Nanomedicine 2010;6:324-33.

23. Marchal-heussler L, Sirbat D, Hoffman M. Poly-Ecaprolactone nanocapsules in carteolol ophthalmic delivery. Pharm Res 1993;10:386-90.

24. Usha GK, Sree HN, Balakeshwa R, Prakash RB. Improved intraocular bioavailability of ganciclovir by mucoadhesive polymer based ocular microspheres: Development and simulation process in wistar rats. Daru J Pharm Sci 2015;23:49.

25. Trotta M, Pattarino F, Ignoni T. Stability of drug carrier emulsions containing phosphatidylcholine mixtures. Eur J Pharm Biopharm 2002;53:203-8

26. Klang SH, Frucht PJ, Hoffman A, Benita S. Physicochemical characterization and acute toxicity evaluation of a positively-charged submicron emulsion vehicle. J Pharm Pharmacol 1994;46:986-93.

27. Velichka A, Plamen Z, Plamen K, Margarita K. Eye drops with nanoparticles as drug delivery systems. Int $\mathrm{J}$ Pharm Pharm Sci 2015;7:431-5.

28. Rizwana K, Aveed A. Evaluation of depigmenting and antierythemic effects of cosmetic emulgels containing raspberry fruit extract on human cheek skin. Int J Pharm Pharm Sci 2016;9:236-8. 